\title{
8
}
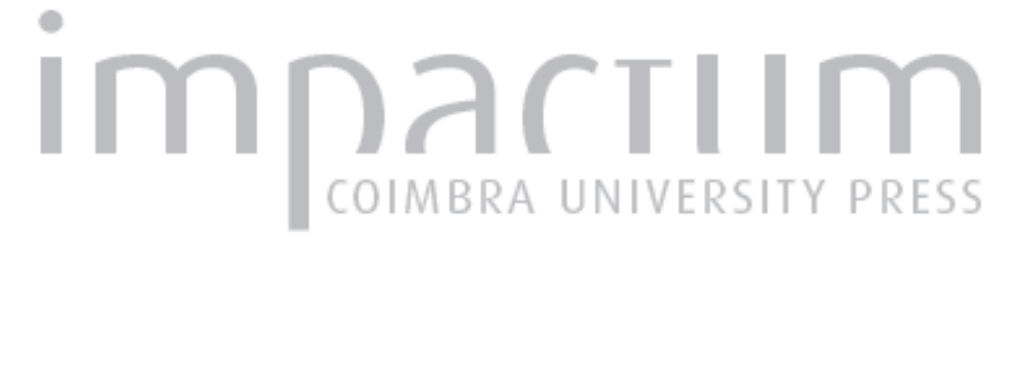

\section{A concessão de direito real de uso e a concessão de uso especial para fins de moradia}

\author{
Autor(es): $\quad$ Rosa, Waleska Marcy \\ Publicado por: Universidade Católica de Petrópolis \\ URL \\ persistente: \\ URI:http://hdl.handle.net/10316.2/33870 \\ DOI: \\ DOI:http://dx.doi.org/10.14195/2175-0947_2-1_8
}

Accessed : $\quad$ 26-Apr-2023 11:38:32

A navegação consulta e descarregamento dos títulos inseridos nas Bibliotecas Digitais UC Digitalis, UC Pombalina e UC Impactum, pressupõem a aceitação plena e sem reservas dos Termos e Condições de Uso destas Bibliotecas Digitais, disponíveis em https://digitalis.uc.pt/pt-pt/termos.

Conforme exposto nos referidos Termos e Condições de Uso, o descarregamento de títulos de acesso restrito requer uma licença válida de autorização devendo o utilizador aceder ao(s) documento(s) a partir de um endereço de IP da instituição detentora da supramencionada licença.

Ao utilizador é apenas permitido o descarregamento para uso pessoal, pelo que o emprego do(s) título(s) descarregado(s) para outro fim, designadamente comercial, carece de autorização do respetivo autor ou editor da obra.

Na medida em que todas as obras da UC Digitalis se encontram protegidas pelo Código do Direito de Autor e Direitos Conexos e demais legislação aplicável, toda a cópia, parcial ou total, deste documento, nos casos em que é legalmente admitida, deverá conter ou fazer-se acompanhar por este aviso.

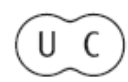



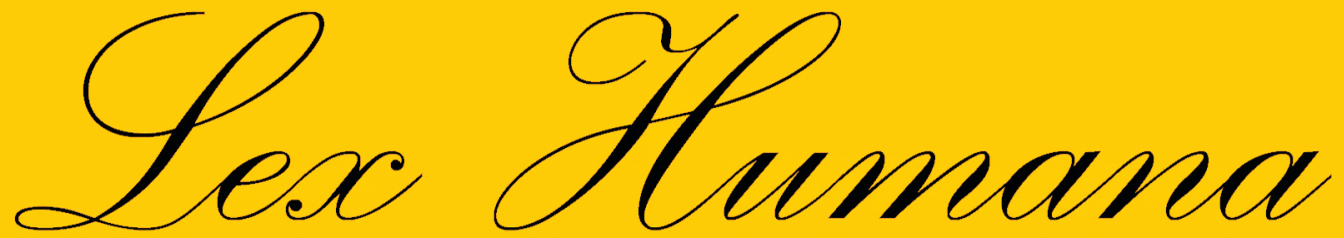

Revista do Programa de Pós-Graduação em Direito da UCP

ISSN(e) 2175-0947

Universidade Católica de Petrópolis Rua Benjamin Constant, 213 - Petrópolis - Centro CEP 25610-130

Tel: (24) 2244-4000 E-mail: lexhumana@ucp.br 


\section{A Concessão de Direito Real de Uso e a ConCEssão de USo ESPECIAL PARA Fins de MORADIA}

Dra. Waleska Marcy Rosa ${ }^{1}$

Resumo

O presente texto pretende diferenciar a concessão do direito real de uso e a concessão de uso especial para fins de moradia. Em relação à concessão de direito real de uso, há bibliografia já sedimentada a respeito do assunto, tendo em vista que é disciplinada pelo Decreto-Lei 271, de 28 de fevereiro de 1967. Quanto à concessão de uso especial para fins de moradia, o mesmo não ocorre, pois a Medida Provisória 2.220, de 04 de setembro de 2001 não vem sendo, em regra, objeto de pesquisas suficientes para a produção de literatura. Além de sua relevância jurídica, a concessão de uso especial para fins de moradia possui enorme relevância social, tendo em vista a situação da habitação urbana no Brasil e a necessidade de regularização de áreas públicas com ocupações consolidadas, o que justifica a abordagem deste assunto. A identificação das diferenças entre os dois tipos de concessão permite seu melhor manejo, de acordo com os limites e possibilidades de cada um no que se refere à regularização fundiária urbana.

\footnotetext{
1 Doutorado em Direito (Direito, Estado e Cidadania) pela Universidade Gama Filho - RJ. É professora adjunta da Universidade Católica de Petrópolis (UCP) e professora titular do Centro Universitário Serra dos Órgãos (UNIFESO). 
Palavras-chave: Concessão; direito real; uso especial; moradia.

Abstract

This paper seeks to differentiate both the concession of the real right use and the concession of the special use for dwelling purposes. As for the concession of the real right of use, there is already a consolidated bibliography on the subject, considering that it is ruled by the Decree Law 271, February 28, 1967. But that is not true in the case of the concession of the special use for dwelling purposes, as the Provisional Measure 2220, of September 4, 2001 has not being object of sufficient research in order to produce specialized literature. Beyond its legal significance, the concession of the special use for dwelling purposes has great social relevance, if is considered the urban housing situation in Brazil and the need for regularization of public areas with consolidated occupations, hence the approach to this subject. The identification of the differences between the two types of concessions allows a better management according to the limits and possibilities of each one in relation to urban land regularization.

Keywords: Concession; real right; special use; dwelling purposes.

\section{Introdução}

O presente texto pretende abordar aspectos do Estatuto da Cidade (Lei n. 10.257, de 10 de julho de 2001), desenvolvendo o tema A concessão do direito real de uso e a concessão de uso especial para fins de moradia.

Entendeu-se importante, para o contexto, além de situar o tema no ordenamento jurídico brasileiro e demonstrar sua relevância 
social, justificar sua relevância, a ponto de tal objeto de pesquisa ser levado a publicação. Para tanto, antes de adentrar o assunto, cabem algumas considerações a respeito dele, o que será feito no item 2 .

No que se refere à metodologia através da qual foi elaborado este trabalho, importa salientar inicialmente a questão referente à pesquisa desenvolvida, para, posteriormente, justificar a forma através da qual o tema foi tratado. Tal inversão se impõe, tendo em vista o levantamento bibliográfico preparado para este trabalho.

Em busca de bibliografia a respeito do assunto, surgiu uma dificuldade: a escassez de obras específicas a respeito do tema abordado. Tal situação, provavelmente, ocorre devido ao fato de que ainda há muito que se pesquisar e, consequentemente, publicar, a respeito do Estatuto da Cidade. Além disso, a Medida Provisória 2.220, de 04 de setembro de 2001 não vem sendo, salvo algumas exceções², objeto de muitos estudos, pesquisas e debates. Desta maneira, não há uma farta bibliografia a seu respeito, sendo, frequentemente tratada como um elemento acessório em obras referentes ao Estatuto da Cidade.

Em relação à concessão de direito real de uso, há bibliografia já sedimentada a respeito do assunto, tendo em vista que é disciplinada pelo Decreto-Lei 271, de 28 de fevereiro de 1967.

O levantamento bibliográfico foi realizado na Biblioteca do Tribunal de Justiça do Estado do Rio de Janeiro, no Sistema de Bibliotecas da Universidade do Estado do Rio de Janeiro, na Biblioteca da Pontifícia Universidade Católica do Rio de Janeiro e na Biblioteca da Universidade Católica de Petrópolis. Justifica-

2 Talvez a principal exceção pode ser verificada em São Paulo. Naquele município, vêm sendo implantadas importantes ações no sentido de efetivar a concessão de uso especial para fins de moradia. O Instituto Pólis vem desenvolvendo material de orientação para regularização de áreas de ocupação irregular por meio da concessão de uso especial para fins de moradia. Além disso, a Defensoria Pública daquele Estado da Federação vem atuando no sentido de maximizar a utilização deste instrumento de regularização fundiária urbana. 
se a escolha das três primeiras por serem as bibliotecas abertas ao público mais conceituadas da cidade do Rio de Janeiro. No que se refere especificamente ao sistema de bibliotecas da UERJ, a escolha se deu pelo fato da referida Instituição de Ensino Superior possuir um conceituado programa de Pós-graduação Stricto Sensu na área de Direito da Cidade. Quanto à Biblioteca da Universidade Católica de Petrópolis, além de estar situada na Instituição de Ensino Superior (IES) na qual a autora leciona, a referida IES possui um programa de pesquisa institucional voltado para a investigação científica sobre a propriedade imobiliária na cidade, o que a torna uma referência sobre o assunto.

A bibliografia levantada foi trabalhada do seguinte modo: após leitura das obras, partiu-se para a elaboração do presente texto, elaborado a partir de análises das informações obtidas através da leitura do material elencado ao final deste texto. Por este motivo, poucas referências serão feitas, já que se buscou a construção de um texto com estilo mais autoral.

Conforme se depreenderá do trabalho, além de sua relevância jurídica, a concessão de uso especial para fins de moradia possui enorme relevância social, tendo em vista a situação da habitação urbana no Brasil. Mais uma vez, então, é destacada a importância da compreensão do instituto, tendo em vista sua serventia social.

Justificada a importância do tema deste trabalho, cumpre apresentar a estrutura utilizada para a elaboração do texto. Optou-se por um trabalho curto, quase um ensaio, tendo em vista duas questões. A primeira diz respeito à forma de proposição do tema (A concessão de direito real de uso e a concessão de uso especial para fins de moradia), que pressupõe uma análise comparativa. Sendo assim, caminhouse no sentido de tentar traçar um paralelo entre as duas formas de concessão, de maneira a se verificar o que as aproxima e o que as 
diferencia. Para tanto, partiu-se das características e pressupostos de cada uma delas. Ao final do trabalho, é apresentado um quadro sinóptico com as diferenças e semelhanças.

O segundo motivo da opção pela apresentação do trabalho foi a exígua bibliografia a respeito da concessão de uso especial para fins de moradia, conforme justificado acima.

Feitas todas estas necessárias justificativas, inicia-se a exposição temática.

\section{Considerações iniciais}

A) As condições de vida nas cidades se tornou um dos mais graves problemas enfrentados pela população brasileira, desde o início da urbanização. Nos últimos vinte anos, pode-se verificar um agravamento da situação, causando reflexos negativos na qualidade de vida dos habitantes dos centros urbanos. Estes problemas se referem a diversos aspectos da vida nas urbes: transporte, abastecimento, habitação, saneamento, além de diversos outros. Dentre todas estas questões, salienta-se a moradia, que, principalmente devido ao descaso governamental, gera notícias como as que freqüentemente são publicadas nos jornais de grande circulação do país ${ }^{3}$. Como exemplo, a Folha de São Paulo, afirmou, com base em pesquisa encomendada pelo governo federal e pelo BID (Banco Interamericano de Desenvolvimento $)^{4}$, que a falta de moradia atinge diretamente 20,2

3 Tais fatos se tornam notícia especialmente devido à dimensão de tragédia que freqüentemente assumem, como foi o caso das chuvas que, em abril de 2010, geraram mais de duzentas mortes no Estado do Rio de Janeiro, com destaque para os deslizamentos ocorridos no Morro do Bumba, situado na cidade de Niterói. Naquele local, havia um assentamento irregular sobre um lixão desativado. Com a falta de fiscalização por parte do Poder Público e com as ações demagógicas que, muitas vezes, envolvem tais situações, ao longo do tempo aquela comunidade foi se consolidando em local absolutamente impróprio para moradia, seja pelos riscos de deslizamento, seja pelos riscos de contaminação pelo chorume produzido pela decomposição dos resíduos, caracterísitca típica dos lixões.

A pesquisa foi realizada pela Fundação João Pinheiro (Minas Gerais), com base em dados 
milhões de brasileiros. Para sanar este problema, seriam necessários 6,6 milhões de novas unidades habitacionais ${ }^{5}$.

Paralelamente, o mesmo estudo demonstra que existem 6 milhões de moradias fechadas no Brasil. Tal constatação revela um paradoxo que é fruto da ausência ou, pelo menos, da ineficiência das políticas públicas na área da habitação, sendo certo que a mais marcante das políticas públicas na área foi a ação perpetrada pelo extinto BNH (Banco Nacional da Habitação).

Se é certo que o BNH não atingiu os objetivos para os quais foi criado, também há que se reconhecer que sua extinção deu origem a mais uma lacuna no que se refere às políticas públicas na área da habitação.

Recentemente $^{6}$, no entanto, uma destas lacunas foi suprida. É fato que a situação das políticas públicas na área da habitação deverá se modificar profundamente ${ }^{7}$ a partir da elaboração do Estatuto da Cidade (Lei n. 10.257, de 10 de julho de 2001) que regulamentou os artigos 182 e 183 da Constituição Federal de 1988. A postura governamental que há muito vem sendo mantida, com pouquíssimos ajustes e modificações, não mais se coaduna com o teor do Estatuto da Cidade, diploma jurídico voltado para o

coletados pelo IBGE (Instituto Brasileiro de Geografia e Estatística).

5 BRAGON, Ranier. Falta de moradias afeta $12 \%$ dos brasileiros. Folha de São Paulo, São Paulo, 20 de jan. 2002. Folha Cotidiano, p. C1.

6 Embora o Estauto da Cidade seja uma lei de 2001, portanto prestes a completar nove anos, ainda pode ser considerada recente, seja pelo fato de que, em termos de sedimentação e consensualização a respeito de nova regulamentação jurídica, nove anos não podem ser considerados muito tempo; seja pelo fato de que ainda será necessário um longo lapso temporal para que o Estado brasileiro, pouco afeito ao planejamento no que se refere às questões urbanas, consiga tornar efetivo o Estatuto da Cidade.

$7 \quad$ Apesar de já terem se passado quase nove anos desde a vigência do Estatuto da Cidade, apesar da Lei que regula o Fundo Nacional de Habitação de Interesse Social (FNHIS) e apesar do Programa Minha Casa, Minha Vida (parte integrante do denominado Programa de Aceleração do Crescimento (PAC) 2), não se pode dizer que foram percebidas grandes modificações no que se refere às políticas públicas para moradia. No entanto, deve-se ressalvar que o FNHIS e o Programa Minha Casa, Minha Vida são bastante recentes, respectivamente, de 2007 e 2009. 
reconhecimento da cidadania e das necessidades do indivíduo que habita os centros urbanos.

Nas determinações do Estatuto, está presente a questão habitacional, regulada através de diversos instrumentos previstos pelo referido diploma legislativo e pela própria Constituição Brasileira. Dentre estes instrumentos encontra-se a concessão de uso especial para fins de moradia.

A Lei 10.257, de 10 de julho de 2001, em seus artigos 15 a 20, regulamentou o referido instrumento. Entretanto, tais artigos foram vetados pelo Chefe do Executivo, sob o argumento de serem contrários ao interesse público ${ }^{8}$. Para suprir a lacuna deixada pelo veto, Fernando Henrique Cardoso editou, em 04 de setembro de 2001, a Medida Provisória 2.220, regulamentando o instrumento da concessão de uso especial para fins de moradia, previsto na alínea h do inciso $\mathrm{V}$ do artigo $4^{\circ}$ do Estatuto da Cidade e no artigo 183, parágrafo $1^{\circ}$ da Constituição Brasileira de 1988.

Uma das questões que surgiram a respeito da concessão de uso especial para fins de moradia é a adequação entre o instrumento de regularização fundiária previsto pela Medida Provisória 2.220 e o regime jurídico dos bens públicos. Sabe-se que o ordenamento jurídico pátrio impede a prescrição de bens públicos, com base na indisponibilidade do interesse público. O atual Código Civil, em vigor desde 11 de janeiro de 2003, determina, em seu artigo 102, que os bens públicos não estão sujeitos à usucapião9 ${ }^{9}$ A própria Constituição Brasileira possui dispositivo no mesmo sentido: o $\S 3^{\circ}$ do artigo 183 determina que os imóveis públicos não serão adquiridos por usucapião.

\footnotetext{
8 Para verificar as razões do veto, ver MEDAUAR, Odete; ALMEIDA, Fernando Dias Menezes (Coord.). Estatuto da Cidade: Comentários. 1. Ed. São Paulo: Revista dos Tribunais, 2002, p. 204-210. 
B) Embora seja claro que o ordenamento jurídico brasileiro não admite a possibilidade de usucapião de bens públicos, há que se diferenciar a aquisição do domínio da aquisição de outros direitos inerentes ao domínio. Para Carvalho Santos, através da usucapião pode-se adquirir não somente o domínio pleno, mas também outros direitos reais, como o uso ${ }^{10}$. Portanto, de acordo com o que prescreveu a MP 2.220, estar-se-ia diante de uma forma de usucapião de bem público? Se for, qual seria o fundamento desta inovação no ordenamento jurídico brasileiro? Esta inovação seria possível, diante do que prevê a Constituição Brasileira, o Código Civil e o próprio Direito Administrativo? Estaríamos diante de uma virada de Copérnico no regime dos bens públicos no Brasil?

É importante deixar claro que o estudo a respeito deste instrumento torna-se relevante porque há muitas ocupações para fins de moradia em bens públicos, o que torna mais difícil a regularização da ocupação, do uso e da propriedade por parte dos possuidores diretos destes bens.

C) Podem ser identificadas, de imediato, algumas soluções para os questionamentos apresentados no item anterior. Algumas possibilidades passam a ser expostas.

Inicialmente, cabe ressaltar que, como já verificado, a Medida Provisória 2.220/2001 estabelece um prazo prescricional aquisitivo. Cumprido este prazo e os outros requisitos previstos no diploma normativo, o indivíduo terá o direito de uso que, não sendo respeitado pela Administração Pública, poderá ser exigido perante o Poder Judiciário. Estar-se-ia, desta forma, diante de caso de concessão de uso especial para fim de moradia pelo decurso do tempo e não devido à discricionariedade da Administração Pública. A concessão

$\overline{10}$ SANTOS, J. Carvalho. Código Civil brasileiro interpretado. 1. ed. v. VII. Rio de Janeiro: Freitas Bastos, 1961, p. 427.

http://www.ucp.br/html/joomlaBR/lexhumana/lexhumana.htm 
de uso, neste caso, portanto, não passa a existir através de um contrato administrativo, mas pelo simples decurso do tempo, o que vincula a Administração Pública.

Embora não pareça necessário, é importante deixar claro que o indivíduo que atende os requisitos do artigo $1^{\circ}$ da Medida Provisória 2.220/2001 não adquire o domínio do bem público, mas apenas o direito de usá-lo para morar. Desta forma, o bem deve ser utilizado para um único fim: a moradia. Se houver desvio na utilização, o uso do bem poderá ser retomado pela Administração Pública.

Assim, aparentemente, estar-se-ia diante de prescrição aquisitiva do direito real de uso sobre bem público em favor dos possuidores. Entretanto, também aparentemente, as normas contidas na Medida Provisória vão de encontro ao regime dos bens públicos e à Constituição Brasileira que, em seu artigo 183, § $3^{\circ}$, determina que os imóveis públicos não podem ser adquiridos por usucapião.

Tais hipóteses justificam o paralelo que se passa a traçar entre a concessão de direito real de uso e a concessão de uso especial para fins de moradia.

3. A concessão de direito real de uso e a concessão de uso especial para fins de moradia

A) Antes de iniciar as diferenciações, é importante ressaltar, que tendo em vista que o Estatuto da Cidade prevê a concessão de uso especial para fins de moradia somente em relação a imóveis públicos, para se traçar o paralelo com a concessão de direito real de uso considerar-se-á somente a concessão de direito real de uso de bem público pelo particular.

B) A concessão de direito real de uso, prevista no art. $7^{\circ}$ do Decreto-lei 271, de 28 de fevereiro de 1967, 
é o contrato pelo qual a Administração transfere, como direito real resolúvel, o uso remunerado ou gratuito de terreno público ou do espaço aéreo que o recobre, para que seja utilizado com fins específicos por tempo certo ou por prazo indeterminado ${ }^{11}$.

Já a concessão de uso especial para fins de moradia está prevista no art. $1^{\circ}$ da Medida Provisória 2.220, de 04 de setembro de 2001, que regula o referido instituto, tendo em vista que os dispositivos do Estatuto da Cidade que cuidavam do mesmo instituto foram vetados pelo Presidente da República. Nisto já reside a primeira diferença entre os institutos, que, portanto, não se confundem, como se depreenderá do presente texto.

A partir da definição transcrita acima, verifica-se que o direito real de uso é decorrente de um contrato administrativo, portanto, depende da discricionariedade do Poder Público que um determinado bem público seja concedido para uso pelo particular. Neste ponto já reside uma das principais diferenças entre a concessão de direito real de uso e a concessão de uso especial para fins de moradia: enquanto a primeira é decorrente da vontade da Administração, gerando, portanto, um acordo de vontades (o contrato administrativo), a segunda é decorrente de direito subjetivo do possuidor, surgindo, assim, para a Administração a prática de um ato administrativo vinculado.

A vinculação da Administração surge porque o decurso do tempo previsto na MP 2.220 - cinco anos (art. $1^{\circ}$ ) - gera para o possuidor direito subjetivo à concessão de uso especial para fins de

11 MELlO, Celso Antônio Bandeira de. Curso de Direito Administrativo. 7. ed. São Paulo: Malheiros, 1995, p. 535.

http://www.ucp.br/html/joomlaBR/lexhumana/lexhumana.htm 
moradia. Portanto, negando-se a Administração a conferir o título de concessão, ou omitindo-se, o possuidor poderá pleitear em juízo a declaração da concessão de uso especial para fins de moradia. A própria MP 2.220, em seu art. $6^{\circ}, \S 3^{\circ}, \quad$ reconhece que a sentença é declaratória o que confirma a aquisição do direito pelo decurso do tempo.

A concessão de direito real de uso decorre de algum dos fins fixados em lei, quais sejam: urbanização, edificação, industrialização, cultivo ou qualquer uso que traduza interesse social. Já no caso da concessão para fins de moradia, o escopo é exclusivamente este: que o possuidor utilize o bem público com o fim único de morar, de nele habitar, fazer sua residência. Por óbvio que, nos dois casos, em última análise estar-se-á atingindo o interesse social, na medida em que é de interesse geral que todas as pessoas que compõem a sociedade possam ter condições de habitação.

Nos dois casos são previstas sanções para a não utilização do bem de acordo com a finalidade que gerou a concessão. No caso da concessão de direito real de uso, se seus objetivos não forem respeitados, há a reversão do uso para o ente que o concedeu. $\mathrm{Na}$ hipótese de concessão especial de uso para fins de moradia, o desvio de finalidade gera a extinção da concessão. Ocorre também a extinção, quando o concessionário adquire a propriedade de outro imóvel ou adquire a concessão de uso de outro imóvel urbano ou rural. É o que se depreende do art. $8^{\circ}$ da MP 2.220. Portanto, nos dois casos de concessão, esta se encontra vinculada à utilização do bem tal como previsto na norma. Identifica-se, assim, um ponto de aproximação entre as duas espécies de concessão.

As duas formas de concessão incidem sobre imóveis públicos. No entanto, no caso da concessão de direito real de uso, 
pode-se verificar, segundo Celso Antônio Bandeira de Mello, um certo "parentesco" com o direito de superfície ${ }^{12}$, tendo em vista que o art. $8^{\circ}$ do Decreto-lei 271 prevê que poderá também ser concedido o uso do espaço aéreo sobre a superfície de terrenos, considerada autonomamente e não vinculada à concessão do terreno.

Outra característica que aproxima as duas formas de concessão é o fato de possuírem natureza de direito real, tendo em vista que assim previsto nas normas que os regulamentam. Sendo direito real, possui as características que lhe são inerentes, ou seja, sua imediata adesão à coisa, sobre a qual não poderá incidir outro direito da mesma espécie. Além disso, tratando-se de direito real, presente estará o direito de seqüela que será oponível erga omnes. Por fim, dentre as características inerentes aos direitos reais, encontrase, também, a proteção do direito através de ação real. Tudo isto retira, das duas formas de concessão, qualquer caráter meramente obrigacional.

Tratando-se de direito real, nos dois casos é necessária a inscrição do instrumento de concessão no Registro de Imóveis, a fim de que possa produzir efeitos contra terceiros. Neste caso, será inscrito o termo administrativo, no caso da concessão de direito real de uso e o termo administrativo ou a sentença judicial, no caso da concessão de uso especial para fins de moradia.

Aproxima, ainda, as duas formas de concessão, o fato de ambas serem transmissíveis inter vivos ou causa mortis, desde que, nas duas situações sejam respeitados os fins da concessão. Caso contrário, estar-se-ia diante de desvio na utilização do bem, gerando as conseqüências já mencionadas.

Por fim, diferenciam as duas formas de concessão os

12 MELLO, Celso Antônio Bandeira de. Curso de Direito Administrativo. 7. ed. São Paulo: Malheiros, 1995, p. 535.

http://www.ucp.br/html/joomlaBR/lexhumana/lexhumana.htm 
pressupostos para que sejam elas efetivadas. No caso da concessão de direito real de uso, salvo nos casos legais de dispensa, é indispensável o processo licitatório, a fim de que o Poder Público possa conceder o uso do bem. No caso da concessão de uso especial para fins de moradia, não há que se falar em licitação. Basta que os pressupostos de concessão tenham sido preenchidos pelo concessionário. Ou seja, o concessionário deve preencher os requisitos elencados no art. $1^{\circ}$ da MP 2.220: ter completado, até 30 de junho de 2001, cinco anos ininterruptos na posse pacífica do imóvel público, que deve ter, no máximo, duzentos e cinqüenta metros quadrados. Além disso, a posse deve ter como fim a moradia própria ou da família, não podendo o possuidor ser proprietário ou concessionário de outro imóvel, urbano ou rural.

\section{Considerações finais}

Em linhas gerais, são estes os principais traços diferenciadores das duas formas de concessão aqui tratadas: a concessão de direito real de uso e a concessão de uso especial para fins de moradia.

Abaixo, segue quadro sinóptico que permite visualizar as diferenças e aproximações existentes entre os dois tipos de concessão.

\begin{tabular}{|l|l|}
\hline Concessão de direito real de uso & $\begin{array}{c}\text { Concessão de uso especial para fins de } \\
\text { moradia }\end{array}$ \\
\hline - Contrato administrativo & $\begin{array}{l}\text { - Ato administrativo vinculado } ~ \\
\text { subjetivo direito }\end{array}$ \\
\hline - Decreto-lei 271, de $28 / 02 / 1967$ & - Medida Provisória 2220, de 04/09/2001 \\
\hline - Outorga de direito real & - Direito Real \\
\hline $\begin{array}{l}\text { - Fins fixados em lei - urbanização, } \\
\text { edificação, industrialização, cultivo } \\
\text { ou qualquer uso que traduza } \\
\text { interesse social }\end{array}$ & - Finalidade exclusiva de moradia \\
\hline
\end{tabular}




\begin{tabular}{|l|l|l|}
\hline $\begin{array}{l}\text { - Incide sobre terrenos públicos } \\
\text { ou sobre o espaço aéreo acima da } \\
\text { superfície }\end{array}$ & - Incide sobre imóveis públicos \\
\hline $\begin{array}{l}\text { - Reversão do uso para a } \\
\text { Administração se não forem } \\
\text { respeitados os objetivos da } \\
\text { concessão }\end{array}$ & $\begin{array}{l}\text { - Extinção: * desvio de finalidade; } \\
\text { * aquisição da propriedade de } \\
\text { outro imóvel }\end{array}$ \\
\hline $\begin{array}{l}\text { - Direito real transmissível por ato } \\
\text { inter vivos ou causa mortis, desde } \\
\text { que observados os fins da concessão }\end{array}$ & $\begin{array}{l}\text { - Direito real transferível por ato inter } \\
\text { vivousa mortis }\end{array}$ \\
\hline - Instrumento: termo administrativo & $\begin{array}{l}\text { - Instrumento: termo administrativo ou } \\
\text { sentença judicial declaratória }\end{array}$ \\
\hline - Inscrição no Registro de Imóveis & \begin{tabular}{l} 
- Inscrição no Registro de Imóveis \\
\hline - Necessidade de licitação, salvo nos \\
casos legais de dispensa
\end{tabular} & $\begin{array}{l}\text { - Pressupostos: } \\
\text { 1) posse por cinco anos até 30/06/2001; } \\
\text { posse ininterrupta e pacífica; } \\
\text { 3) imóvel urbano público de 250 m2; } \\
\text { 4) uso para fins de moradia própria ou da } \\
\text { família; } \\
\text { 5) não ter o possuidor a propriedade de } \\
\text { outro imóvel. }\end{array}$ \\
\hline
\end{tabular}

\section{Referências Bibliográficas}

BASTOS, Celso Ribeiro. Curso de Direito Administrativo. 1. ed. São Paulo: Saraiva, 1994.

BRASIL. Estatuto da Cidade: guia para implementação pelos municípios e cidadãos. 1. ed. Brasília: Câmara dos Deputados, Coordenação de Publicações, 2001.

CARVALHOFILHO, José dosSantos. Manual de Direito Administrativo. 4. ed. Rio de Janeiro: Lumen Juris, 1999. 
DALLARI, Adilson Abreu; FERRAZ, Sérgio (Coord.). Estatuto da cidade: comentários à Lei Federal 10.257/2001. 1. ed. São Paulo: Malheiros, 2002.

GASPARINI, Diógenes. Direito Administrativo. 4. ed. São Paulo: Saraiva, 1995.

MEDAUAR, Odete. Direito Administrativo Moderno. 3. ed. São Paulo: Revista dos Tribunais, 1999.

MEIRELLES, Hely Lopes. Direito Administrativo Brasileiro. 20. ed. São Paulo: Malheiros, 1995.

MOREIRANETO, Diogo deFigueiredo. Cursode Direito Administrativo. 11. ed. Rio de Janeiro: Forense, 1997.

MUKAI, Toshio. O Estatuto da Cidade: anotações à Lei n. 10.257, de 10 de julho de 2001. São Paulo: Saraiva, 2001.

OSÓRIO, Letícia Marques (Org.). Estatuto da cidade e reforma urbana: Novas perspectivas para as cidades brasileiras. 1. ed. Porto Alegre: Sérgio Fabris, 2002.

PIETRO, Maria Sylvia Zanella Di. Direito Administrativo. 5. ed. São Paulo: Atlas, 1995.

Uso privativo de bem público por particular. 1. ed. São Paulo: Revista dos Tribunais, 1983. 